\title{
ABOUT PROBLEM OF STUDYING THE LINGUISTIC PERSONALITY IN MODERN RUSSIAN LINGUISTICS
}

\author{
Alena Ju. Nikitina ${ }^{{ }^{*}}$, Olga A. Petrova ${ }^{2}$, Tatyana N. Romanova ${ }^{3}$, Inna B. Getskina ${ }^{4}$ \\ Margarita V. Emelianova ${ }^{5}$, Anzhelika G. Abramova ${ }^{6}$ \\ ${ }^{1}$ Assoc. Prof., Chuvash State University, RUSSIA, alyona.nikitina@gmail.com \\ ${ }^{2}$ Assoc. Prof., Chuvash State University, RUSSIA, zadumka@mail.ru \\ ${ }^{3}$ Assoc. Prof., Chuvash State University, RUSSIA, romanovatn1@mail.ru \\ ${ }^{4}$ Assoc. Prof., Chuvash State University, RUSSIA, perevod_05@mail.ru \\ ${ }^{5}$ Assoc. Prof., Chuvash State University, RUSSIA, marg_emel@yahoo.com \\ ${ }^{6}$ Assoc. Prof., Chuvash State University, RUSSIA, foreign-languages-department@mail.ru \\ ${ }^{*}$ Corresponding Author
}

\begin{abstract}
The article is devoted to the study of the features of the approach to the study of the linguistic personality in modern linguistics. The term linguistic personality is being developed by many scientists and is firmly established in the science of language. It is assumed that it happens due to the anthropological orientation of linguistics today. The multilevel and complexity of the problem is determined by the fact that in modern linguistics there is still no defined approach to the definition of this term. The variety of interpretations of this concept is because of various aspects of its study, characteristics and comparison (comparison with a communicative, speech personality, etc.). The presence of many interpretations indicates the ambiguity of the term, as well as the desire of linguists to avoid polysemy, which is undesirable for the terminological apparatus of the language. Nevertheless, it is noted that the appearance of the concept of a linguistic personality and its active development played a huge role in the further development of linguistics, led to the emergence of many related sciences at the junction of linguistics and other areas of scientific knowledge. The article examines and analyzes the various approaches to the typology of linguistic personalities existing in linguistics. In the course of the study, it was revealed that in modern linguistics, researchers take the speech strategies of the individual, the national principle, age, sex, the principle of individuality / collectivity, etc. as the basis for the classification of types of linguistic personality. Despite the presence of a large number of approaches to the definition of the concept of a linguistic personality, the authors of the article, having analyzed modern concepts for the definition, study and classification of types of a linguistic personality, revealed that the most developed and generally recognized among them is the three-level model of a linguistic personality proposed by the linguist $\mathrm{Yu}$. N. Karaulov in the monograph "Russian language and linguistic personality" (1987), according to which the researcher proposes to study the linguistic personality at the verbal-semantic, linguo-cognitive and pragmatic levels.
\end{abstract}

Keywords: linguistics, linguistic personality, linguoculturology, verbal-semantic level, linguo-cognitive level, pragmatic level.

\section{INTRODUCTION}

At present, the humanities, including linguistics, are characterized by an ever-growing interest in the problem of studying the human personality, that is, they are characterized by a pronounced anthropocentricity. Thus, the current state of linguistic research is largely determined by the desire to describe a language in close connection with its native speaker, since, according to Yu. N. Karaulov, "it is impossible to know the 
language itself without going beyond it, without turning to its creator, bearer, user - to a person, to a specific linguistic personality" (Karaulov, 2007, p. 7). In this regard, one of the central concepts of linguistics is becoming "linguistic personality", and one of the urgent tasks of modern science is the study of the personality who creates the text.

In modern science, the concept of a linguistic personality has become a full-fledged object of study of linguistics. The breadth of approaches to the definition of this term, the variety of research principles (national, cognitive, communicative, pragmatic, linguoculturological aspects), as well as methods of classification of types (typology) of a linguistic personality indicate the great interest of linguists in the problems of a comprehensive description and analysis of a linguistic personality. Turning to the study of the specifics of a particular person's speech, taking into account his cognitive and pragmatic intentions became one of the most developing areas of modern linguistics.

\section{RESULTS}

The term "linguistic personality" from the 80 s of the last century to the present is one of the most popular and regularly used. In science, interest in the role of the speaking person in the communication process is increasing.

Modern linguistics is characterized by attention to the fact of human interaction as a representative of a certain society with the language that he uses, as a result of that a social and speech portrait of a person as a whole is created. Social, psychological, cognitive, pragmatic aspects of human (personality) speech behavior and their reflection in the linguistic picture of the world, as well as the language used by people in their professional activities, become the subject of increasing interest of researchers. It is no coincidence that in modern linguistics there are many works devoted to the study of the peculiarities of the linguistic personality of various spheres of human activity: this is the linguistic personality of a politician (in this regard, the specificity of political discourse is also considered), a writer, a schoolchild, a student, a person studying foreign languages (the researcher V. P. Furmanova introduces the concept of cultural and linguistic personality (Furmanova, 1994)), etc.

In modern science after Yu. N. Karaulov the linguistic personality is understood as "a set of human abilities and characteristics that determine the creation and perception of speech works (texts), which differ in: a) the degree of structural and linguistic complexity, b) the depth and accuracy of the reflection of reality, c) a certain target orientation" (Karaulov, 1989, p. 3).

The relevance of studying the linguistic personality is due to the fact that in each separately taken linguistic personality not only its individual qualities are revealed, but also the general features of the functioning and development of the language in different eras. Depending on texts the researcher refers to, the linguistic personality can be represented in diachrony and synchrony. So, any historical person who left a noticeable mark on the development of culture, history, and national self-awareness of the people is an interesting model for linguistic research.

V. A. Maslova emphasizes the great importance of the appearance of the concept of linguistic personality for the development of linguistics as a whole, because it led to the appearance of such new directions as linguistic personology, biolinguistics, semiosocial psychology, etc. (Maslova, 2007, p. 49).

However, despite the growing interest in the study of the linguistic personality, it should be noted that in linguistics there is still no single approach to the definition of this term, which is due to the multilevel and complexity of the problem.

For the first time this concept in Russian linguistics was used in 1930 in the work of V. V. Vinogradov "About the Language of Fiction". He used two directions in the study of linguistic personality - he wrote about the personality of the author and the personality of the character. However, his work did not provide a definition of the concept of linguistic personality.

In modern science, researchers note the multilevel and multifaceted nature of the concept of linguistic personality, which "includes mental, social, ethical components refracted through the linguistic system" (Maslova, 2001, p. 119). It should be said that, despite the fundamental nature of this concept noted by many researchers, its definition as a "pivotal system-forming philological concept" (Kochetkova, 1996, p. 15), there is also a different opinion on this issue. For example, V. L. Kraev believes that the phrase "linguistic personality" is terminologically unsuccessful, corresponding to the stage of "general uncertainty" of the research process (Kraev, 1991, p. 110), and V. A. Chudinov says that this term is "scientifically untenable", redundant, "since there is no "languageless personality" (Chudinov, 2007).

In general, in science, we can talk about two conceptual approaches to the definition of the concept of a 
linguistic personality and its study: linguodidactic, on the one hand, and linguoculturological, on the other. In the concept of linguoculturology, "a linguistic personality exists in the space of culture, reflected in language, in forms of social consciousness at different levels (scientific, everyday, etc.), in behavioral stereotypes and norms, in objects of material culture, etc. The defining role in culture belongs to the values of the nation, which are concepts of meanings" (Maslova, 2001, p. 118-119). So, in the work of S. G. Vorkachev, it is written about the national-cultural prototype of a speaker of a certain language; linguistic personality is defined as a basic category of linguoculturology, reflecting the "mentality of a generalized native speaker" and providing linguoculturology with a "research tool for recreating the prototypical image of a "speaking person" (Vorkachev, 2001, p. 71). So, from the point of view of the linguocultural approach the totality of individuals makes up the whole image of a linguistic personality. The linguodidactic approach differs: here a person is defined as a set of speech abilities, a linguistic person is characterized as a set of hypostases through which a person is embodied in a language.

In the first half of the 80 s of the XX century, G. I. Bogin characterized the concept linguistic personality as the central concept of linguodidactics and proposed his own model. G. I. Bogin considered, "a linguistic personality is a person analyzed from the point of view of his readiness to perform speech acts, create and receive works of speech" (Bogin, 1984, p. 1).

In the studies of V. I. Karasik we find another approach to interpreting of linguistic personality - a dictionary linguistic personality (Karasik, 2003). According to his concept, a linguistic personality is "a person who exists in the linguistic space, in communication, in the stereotypes of behavior recorded in the language, in the meanings of linguistic units and the meanings of texts" (Karasik, 2003, p. 99). He also notes that in the context of communication a linguistic personality can be considered as a communicative personality, so cognitive and behavioral aspects can be distinguished (Karasik, 2002).

The concept of linguistic personality is also characterized by the breadth of the approach to its definition. Many researchers correlate it with the concept of "communicative personality". So, according to S. A. Sukhikh, a linguistic personality is a "communicative personality", it can be considered as "... a set of features of the verbal behavior of a person who uses language as a means of communication" (Sukhikh, 1998, p. 64).

In the textbook "Linguoculturology" V. A. Maslova singles out the linguistic and communicative personality as two components of the linguistic personality (Maslova, 2001, p. 120). And in the monograph "Homo lingualis in culture," she describes a linguistic personality as "a personality reconstructed in its basic features on the basis of linguistic means" (Maslova, 2007, p. 48), and, in her opinion, "any person who knows a natural human language can simulate as linguistic personality" (Maslova, 2007, p. 48).

In modern linguistic literature, various approaches to the typology of a linguistic personality are also presented. But there isn't any generally accepted approach to classification. K. F. Sedov noted that "the creation of a typology of linguistic personalities capable of reflecting the individual characteristics of the speech behavior of native speakers" is one of "the most urgent tasks facing modern anthropocentric linguistics" (Sedov, 1999, p. 3). Each researcher takes different criteria and dominants as the basis for constructing a typology.

Many linguists offer a typology of a linguistic personality depending on gender, age, social status (including profession), level of education (I. K. Arkhipov, M. N. Panova, M. A. Kancher, etc.). It should be noted that a fairly large number of works are devoted to the study of the linguistic personality in political discourse, as well as in the media.

In modern linguistics, when addressing the issue of linguistic personality, many researchers accept the theory of linguistic personality, described by Yu. N. Karaulov in the monograph "Russian language and language personality" in 1987. In this work, the author shows that this concept is fundamental and systemforming for the description of the national language, and on its basis it is possible to achieve a new synthesis of knowledge about the Russian language, refracted through the structure of the Russian linguistic personality. In linguistics, they also talk about the leading scientific school "Russian language personality" under the leadership of Yu. N. Karaulov, which was founded in 1996. It includes over 30 scientists.

Yu. N. Karaulov offers a three-level model of linguistic personality: verbal-semantic, cognitive (thesaurus) and motivational (pragmatic) levels. The verbal-semantic level reflects the level of proficiency in everyday language. It is represented by individual words, standard phrases; simple formula phrases and creates the impression of the formation and functioning of a linguistic personality. The cognitive level is represented by generalized concepts, large concepts, reflects a more or less systematic world-image of a person, reflecting the hierarchy of his values. It covers the intellectual sphere of the individual, gives the researcher the opportunity through language, through the processes of speaking and understanding to reach knowledge, consciousness, and the processes of human cognition. This level presupposes a reflection of the linguistic 
model of the world of the individual, its thesaurus, and culture. The motivational (or pragmatic) level is represented by the communicative-activity needs of the individual, including the identification, characterization of motives and goals that drive the development of the individual.

Consequently, in the structure of the linguistic personality $\mathrm{Yu}$. N. Karaulov distinguishes lexicon, thesaurus and pragmaticon, although he notes that in practice there is a strong interpenetration of these levels and the boundaries between them are blurred.

According to Yu. N. Karaulov, less developed and most difficult to study in the theory of linguistic personality is the pragmatic level, although the scientist notes that it "plays a dominant role in the hierarchy of levels" (Karaulov, 1987, p. 211). The complexity of his research is determined, in the opinion of the linguist, by the fact that the interests, motives, goals, creative potential of a person are built to a greater extent on emotions, the linguistic expression of which has been poorly studied. At this level, he considers only precedent texts and their various textual transformations, the role of which is as follows: they carry a partial nominative function, are characterized by the emphasis of only one property, expressive richness, and also act as a kind of "amplifying" means in the disclosure of the image (Karaulov, 1987, p. 223). It is noted that the information of the psychological plan of a person, the analysis of which is paramount at the pragmatic level, creates a unique, inimitable aesthetic and emotional-rhetorical flavor of the linguistic personality, determines the valuesetting criteria (Karaulov, 1987, p. 42).

\section{CONCLUSIONS}

Overall, the lack of an unambiguous solution to some issues related to the three-level structure of the linguistic personality and their characteristics, insufficient knowledge of the pragmatic level and a number of other problems indicate that the theory of linguistic personality requires further development.

\section{REFERENCE LIST}

Bogin, G. I. (1984) Model of a linguistic personality in its relation to the varieties of texts.

Vorkachev, S. G. (2001) Linguoculturology, linguistic personality, concept: the formation of an anthropocentric paradigm in Linguistics. Philological Sciences, vol. 1.

Karasik, V. I. (2002) Linguistic circle: personality, concepts, discourse.

Karasik, V. I. (2003) Aspects of linguistic personality. Problems of speech communication.

Karaulov, Yu. N. (1987) Russian Language and language personality.

Karaulov, Yu. N. (1989) Russian linguistic personality and the tasks of its study. Language and personality.

Kochetkova, T. V. (1996) The problem of studying the linguistic personality of the bearer of elite speech culture (review). Stylistic issues, vol. 26.

Kraev, V. L. (1991) Psycholinguistics and intercultural understanding.

Maslova, V. A. (2001) Linguoculturology.

Maslova, V. A. (2007) Homo lingualis in culture.

Sedov, K. F. (1999) Portraits of linguistic personalities in the aspect of their formation (principles of classification and conditions of formation). Questions of Linguistics, vol. 28.

Sukhikh, S. A. (1998) Pragmalinguistic dimension of the communicative process.

Furmanova, V. P. (1994) Intercultural communication and cultural-linguistic pragmatics in the theory and practice of teaching foreign languages.

Chudinov, V. A. (2007) The problem of the language subject. http://chudinov.ru/problema-yazyikovogosubekta. 